\title{
Crímenes de guerra War crimes
}

\author{
Alfredo Liñán Lafuente \\ Universidad Complutense \\ alflinan@ucm.es
}

Recibido / received: 27/01/2016

Aceptado / accepted: 02/03/2016

DOI: http://dx.doi.org/10.20318/eunomia.2016.3292

\begin{abstract}
Resumen
Los crímenes de guerra son comportamientos que vulneran la reglamentación de los conflictos armados. Desde mediados del siglo XIX se comienza a regular, en Convenios internacionales, el trato que se habría de dar a los prisioneros, heridos y población civil así como los modos y medios de combate prohibidos. Surge así el Derecho internacional humanitario, contenido fundamentalmente en los Convenios de Ginebra y el "Derecho de la Haya", que se compone de los Convenios que reglamentan el uso de la fuerza y el modo de conducir los combates en un conflicto armado. La vulneración grave de estos Convenios se considera crímenes de guerra, desde su inicial tipificación en el Estatuto del Tribunal Militar Internacional de Núremberg, pasando por los Tribunales ad-hoc de la ex Yugoslavia y Ruanda, hasta el artículo 8 del Estatuto de Roma.
\end{abstract}

\section{Palabras clave}

Crímenes de guerra, ius in bello, Derecho internacional humanitario, Derecho de la Haya, crímenes internacionales.

\begin{abstract}
War crimes are behaviors that infringe rules of armed conflict. Since the mid-nineteenth century, several International Conventions begins to regulate treatment of the prisoners, wounded and civilians and types of combat prohibited. International Humanitarian Law arises in the Geneva Conventions, and the "Hague law" which regulates the use of force and how must be conducted the fighting in an armed conflict. The grave breach of these Conventions are considered war crimes, from its initial regulation in the Charter of the International Military Tribunal at Nuremberg, through the ad-hoc international tribunals for the former Yugoslavia and Rwanda, to Article 8 of the Rome Statute.
\end{abstract}

\section{Keywords}

War Crimes, ius in bello, International Humanitarian Law, Hague Law, international crimes.

SUMARIO. 1. Introducción. 2. Los crímenes de guerra en los Estatutos de los Tribunales Militares Internacionales de Núremberg y de Tokio. 3. Los crímenes de guerra en los Estatutos de los Tribunales Penales Internacionales Ad-Hoc para la ex Yugoslavia y 
Ruanda. 4. Los crímenes de guerra en el Estatuto de la Corte Penal Internacional. 5. Los crímenes de guerra en el Código Penal Español.

1. Introducción.

La guerra provoca, habitualmente, la suspensión o abolición de determinados derechos apreciados como intangibles en tiempos de paz, imponiéndose por la fuerza y la amenaza de las armas la voluntad de uno de los bandos sobre los otros que participan en el conflicto armado y sobre la población civil. La mutación del ordenamiento jurídico llega a tal extremo que se encuentra permitido matar a otras personas (enemigos), respetando las normas del combate.

A lo largo de la historia, las guerras no sólo han provocado la muerte de quienes componían los ejércitos enfrentados, sino que la devastación, la muerte, las torturas, las violaciones, el pillaje, y demás actos criminales se han extendido hacia la población civil de los territorios en guerra.

Las normas sobre la reglamentación de las contiendas armadas se comenzaron a desarrollar, a nivel internacional, a partir de la segunda mitad del siglo $\mathrm{XIX}$, si bien es cierto que existen ejemplos históricos de códigos de actuación en tiempos de guerra aplicados por determinados Estados y que fueron redactados con la intención de constituir un marco de actuación de lo permitido y lo prohibido en un conflicto armado (Martínez Alcañiz, 2014: 310) ${ }^{1}$.

La preocupación por la suerte de los heridos tras las batallas, la especial lesividad de ciertos proyectiles, o la necesidad de protección de la población civil llevó a los Estados a ponerse de acuerdo en la identificación de unos mínimos que habrían de ser respetados en la guerra, que fueron enunciados en los originarios Convenios de la Haya y en los Convenios de Ginebra, a finales del siglo XIX. Con anterioridad, como recuerda Quintano Ripollés (1955: 513), "Ios actos humanitarios del combatiente, caudillo o soldado eran típicos beau gestes, dignos sin duda de ser cantados por poetas, moralistas o retóricos, pero que en modo alguno vinculaban a nadie, ni menos suponían una norma de carácter consuetudinario, sino quizás todo lo contrario".

El primer instrumento internacional de codificación de un Derecho humanitario a nivel internacional lo constituye la Convención de Ginebra de 22 de agosto de 1864 "Para el mejoramiento de la suerte de los militares heridos de los ejércitos en campaña". A partir de este precedente, tuvieron lugar otros convenios que contribuyeron a la extensión y profundización del Derecho humanitario y al desarrollo de las normas sobre la conducción de las hostilidades, entre las que destacan las Convenciones I y IV de La Haya de 1899 y de 1907, y su Reglamento anejo sobre las leyes y costumbres de la guerra terrestre, cuya vigencia se extiende hasta nuestros días, y las Convenciones de Ginebra de 1906 y las dos de 1929, sobre el trato de prisioneros de guerra y sobre protección a heridos y enfermos en la guerra terrestre.

Por lo tanto, el derecho a al uso de la fuerza o ius ad bellum fue reglamentado por unas normas básicas que habrían de cumplir los Estados participantes en la contienda, creándose de este modo el ius in bello o derecho aplicable en los conflictos armados (Sloane, 2009: 56).

Así, y como idea inicial, se pueden definir los crímenes de guerra como aquellos comportamientos graves que suponen una infracción de ius in bello. E

\footnotetext{
${ }^{1}$ El Código de Lieber de 24 de abril de 1863 aplicable a las fuerzas armadas de Estados Unidos o el Reglamento para el Servicio de Campaña de 1882 de las fuerzas armas españolas son buena muestra de ello, y en donde se propugnaban principios del actual Derecho Internacional Humanitario.
} 
crimen de guerra no debe confundirse con el crimen de agresión ${ }^{2}$, pues este último supone la violación del ius ad bellum al castigarse el inicio ilícito de una guerra, un acto de agresión no permitido por el Derecho internacional contra otro Estado, mientras que el crimen de guerra constituye una violación del ius in bello por las conductas cometidas en el marco del propio conflicto armado.

En el ámbito del ius in bello, se diferencian dos variantes que se distinguen por el objeto de protección. Así, el Derecho internacional humanitario o "Derecho de Ginebra", es el que se centra en la protección de las víctimas de la guerra (población civil, prisioneros, militares heridos y náufragos); y el "Derecho de la Haya" se ocupa del modo en que se conducen las hostilidades y se compone de los convenios y otros instrumentos internacionales que reglamentan el uso de la fuerza (tipo de armas, formas de combate, objetivos protegidos, etc.). No obstante, esta distinción no es precisa, y en muchas ocasiones las normas de ambas regulaciones se superponen, sobre todo a partir de la elaboración de los Protocolos Adicionales a los Convenios de Ginebra pertenecientes, en principio, al derecho humanitario bélico, que incluyen normas relativas a la conducción de las hostilidades (medios, armas, etc.).

El presupuesto para que se pueda cometer un crimen de guerra es que exista un conflicto armado, ya que aquel ha de suponer la infracción grave de las normas que rigen en el contexto bélico. Si no hay guerra - en el sentido laxo del término-, no puede cometerse un crimen de guerra.

2. Los crímenes de guerra en los Estatutos de los Tribunales Militares Internacionales de Núremberg y de Tokio.

La existencia de una reglamentación de la guerra no presupone, de por sí, la existencia de una figura delictiva cuando ésta se quebrante. El proceso de codificación de los crímenes internacionales, donde se incluyen los crímenes de guerra, ha sido un largo camino donde se han tipificado algunos comportamientos contrarios al ius cogens y se han aplicado tanto por tribunales penales nacionales como internacionales.

No obstante, la tipificación de las conductas ilícitas en tiempos de guerra tuvo lugar primero en las legislaciones penales internas (en códigos penales o leyes militares) encaminadas, sobre todo, a juzgar al enemigo que las cometiese en el territorio. Ello permitió, por ejemplo, que tras la Primera Guerra Mundial, y por imperativo del Tratado de Versalles (Liñán Lafuente, 2015: 37-39), se juzgase a militares alemanes en la Corte Suprema de Leipzig por la comisión de crímenes de guerra ${ }^{3}$.

Tras la Segunda Guerra Mundial, los crímenes de guerra adquieren una dimensión internacional al ser considerados como una violación de las leyes y los usos de la guerra y pasan a ser incluidos en el artículo 6. b) del Estatuto del Tribunal Militar Internacional de Núremberg ${ }^{4}$. En la Carta del Tribunal Militar Internacional

\footnotetext{
${ }^{2}$ El crimen de agresión es heredero de la figura del crimen contra la paz que fue incluido en los Estatutos de los Tribunales Militares Internacionales de Núremberg y Tokio.

3 Tras las negociaciones entre los Estados aliados vencedores de la Primera Guerra Mundial y Alemania, se restringió la lista de las personas que serían acusadas. El primer juicio comenzó el 23 de mayo de 1921 y en total se celebraron 9 procesos completos donde se acusó a 12 personas. La mitad fueron declaradas inocentes y ninguno de los demás condenados cumplió una pena superior a 2 años (Albrecht, 1999: 42-43). Una de las causas de las absoluciones fue la asunción de la obediencia debida como causa de exclusión de la responsabilidad penal. Vid. proceso contra el teniente Karl Neuman en The British Cases (1922: 636-637).

${ }^{4}$ El artículo 6. b del Estatuto rezaba del modo siguiente: CRÍMENES DE GUERRA: A saber, violaciones de las leyes o usos de la guerra. En dichas violaciones se incluye el asesinato, los malos
} 
para el Lejano Oriente también fue incluida la tipificación del crimen de guerra de un modo similar en su artículo 5.b), identificando los crímenes de guerra como violaciones de las leyes y costumbres de la guerra.

Como puede apreciarse, nos encontramos con un tipo penal abierto, que directamente remite a las leyes y costumbre de la guerra, identificándolas como Derecho internacional directamente aplicable y exigible a cualquier persona al formar parte del ius cogens. En las sentencias se identificaron los Convenios que componía el ius in bello, remitiéndose el tribunal a los Convenios de Ginebra y de la Haya anteriores a la Segunda Guerra Mundial (Quintano Ripollés, 1955: 577) 5 .

3. Los crímenes de guerra en los Estatutos de los Tribunales Penales Internacionales Ad-Hoc para la ex Yugoslavia y Ruanda.

Los Estatutos de los Tribunales Penales internacionales ad hoc de la ex Yugoslavia (TPIY) y Ruanda (TPIR) incorporan la tipificación del crimen de guerra como crimen internacional. Se ha de tener en cuenta que en la fecha en que estos se aprobaron (1993 y 1994) estaban en vigor, hacía muchos años, los cuatro Convenios de Ginebra de 1949 así como sus protocolos adicionales de 1977, como parte del Derecho internacional humanitario.

Así, el Estatuto del TPIY tipifica los crímenes de guerra en dos artículos distintos. En el artículo 2 castiga las "infracciones graves a la Convención de Ginebra de 14 de agosto de 1949", especificando a continuación las conductas que se consideraran como infracciones graves (torturas, homicidio a la población civil, deportaciones, etc.). Estos comportamientos los distingue, en el artículo 3 del Estatuto, de las "violaciones de las leyes o prácticas de la guerra", identificando como tales - sin que esto impida reconocer otras - el empleo de armas tóxicas, la destrucción sin motivos de ciudades o pueblos, o el pillaje.

En el Estatuto del TPIR los crímenes de guerra se refunden en un solo artículo que se limita a castigar la violación del artículo 3 común a los Convenios de Ginebra y del Protocolo Adicional II (PA) de los Convenios, incluyendo una lista de violaciones (violencia, vida o salud de personas protegidas, tortura, mutilación, etc.), pero advirtiendo, eso sí, que la lista no es exhaustiva, y dejando por tanto el tipo penal abierto.

En ambos Estatutos podemos apreciar que los crímenes de guerra son contravenciones graves de conductas contempladas en los Convenios de Ginebra y otros Convenios que reglamentan los medios, modos y formas de combate permitidos.

4. Los crímenes de guerra en el Estatuto de la Corte Penal Internacional.

El artículo 8 del Estatuto de Roma (ER) tipifica las conductas constitutivas de crímenes de guerra de un modo extenso y detallado, los cuales han de tener lugar en el marco de un conflicto armado, el cual existe, siguiendo la jurisprudencia del

tratos o la deportación para realizar trabajos forzados o para otros objetivos en relación con la población civil de un territorio ocupado o en dicho territorio, el asesinato o malos tratos a prisioneros de guerra o a personas en alta mar, el asesinato de rehenes, el robo de bienes públicos o privados, la destrucción sin sentido de ciudades o pueblos, o la devastación no justificada por la necesidad militar, sin quedar las mismas limitadas a estos crímenes; Disponible en la siguiente dirección (fecha de $\begin{array}{llllll}\text { consulta: } & 14 & \text { de } & \text { enero } & & \\ \text { de }\end{array}$ http://www.cruzroja.es/dih/pdf/estatuto del tribunal militar internacional de nuremberg.pdf

${ }^{5}$ Sirva como ejemplo que uno de los hechos que el Tribunal apreció que habían violado estas leyes de la guerra, fue la promulgación y ejecución del decreto Nach und Nebel que acordaba el traslado de prisioneros de las zonas ocupadas al interior de Alemania, para su posterior aniquilación. 
TPIY $^{6}$, cuando se recurre a la fuerza armada entre Estados o a la violencia armada entre autoridades gubernamentales y grupos armados organizados, o entre semejantes grupos en el interior de un Estado.

El Estatuto de Roma distingue dos escenarios posibles dentro del mismo marco típico: conflicto armado interno y conflicto armado internacional. La diferenciación entre ambos tipos de conflicto tiene un origen histórico, pues tradicionalmente se entendía que el derecho internacional humanitario sólo era aplicable a los conflictos internacionales, considerando las guerras civiles como asuntos internos de los Estados (Werle, 2011: 567 y 581). No obstante, los conflictos internos fueron regulados por primera vez a través del art. 3 común de los Convenios de Ginebra de 1949, y desde entonces han encontrado su reflejo en otros instrumentos internacionales como los Protocolos adicionales a los Convenios de Ginebra (en particular el PA II). A pesar de ello, el artículo 8 ER mantiene la distinción entre ambos tipos de conflictos, reservando unos tipos delictivos para los conflictos internacionales que no son aplicables a los conflictos internos, algo que desde el punto de vista de la antijuridicidad material del tipo de injusto carece, en mi opinión, de sentido. Así, se puede identificar una situación en donde la utilización de escudos humanos es considerada un crimen de guerra si se produce en un conflicto internacional (art. 8.2.b) xxiii) y no se encuentra castigada si se comete en un conflicto armado interno.

Los conflictos armados internacionales son aquellos que surgen entre los Estados, las situaciones de ocupación total o parcial de un Estado frente a otro, así como las guerras de liberación nacional donde los pueblos luchan contra la dominación colonial o las fuerzas de ocupación extranjera.

Los conflictos armados internos son aquellos se desarrollan entre las fuerzas armadas de un Estado y las fuerzas armadas disidentes o grupos armados organizados que, bajo la dirección de un mando responsable, ejerzan sobre una parte de dicho territorio un control tal que les permita realizar operaciones militares sostenidas y concertadas (art. 1 PA II).

Además, y como ejemplo de lo obsoleto que resulta la distinción en el artículo $8 \mathrm{ER}$ del conflicto interno e internacional, la práctica ha demostrado que existen zonas intermedias. Así, la Corte Penal Internacional se ha visto obligada a desarrollar el concepto de conflicto armado internacionalizado o mixto en los casos en que la confrontación se desarrolla entre un Estado y fuerzas armadas rebeldes apoyadas, directa o indirectamente, por otro Estado. En el caso Lubanga, la Corte Penal Internacional estimó que era posible que un grupo pudiese librar en distintas partes del territorio conflictos calificables como internacionales y en otros territorios distintos conflictos identificables como internos, en función de los contrincantes y las circunstancias (Gil Gil, 2015: 791) ${ }^{7}$. En ese caso, se estaría ante conflictos mixtos o paralelos, donde para encuadrar la conducta típica se deberá decidir antes, en qué tipo de conflicto (interno o internacional) se llevó a cabo la acción.

Dentro de esos dos escenarios (conflicto armado interno y conflicto armado internacional) se castigan, por un lado, las violaciones del Derecho internacional humanitario (Derecho de Ginebra) y por otro lado, las infracciones de los usos

\footnotetext{
${ }^{6}$ ICTY Prosecutor v. Duško Tadić. AC, "Decision on the Defence motion for interlocutory appeal on jurisdiction" (IT-94-1-T), 2.10.1995, § 70.

ICC, Prosecutor v. Thomas Lubanga Dyilo, TC I, Judgment (ICC-01/04-01/06-2842), 14.03.2012; También en, ICC, le Procureur c. Germain Katanga, TC II, "Jugement rendu en application de l'article 74 du Statut" (ICC-01/04-01/07), 7.03.2014.
} 
reglamentados en la conducción de las hostilidades (Derecho de la Haya). La estructura de los crímenes de guerra se podría resumir del modo siguiente:

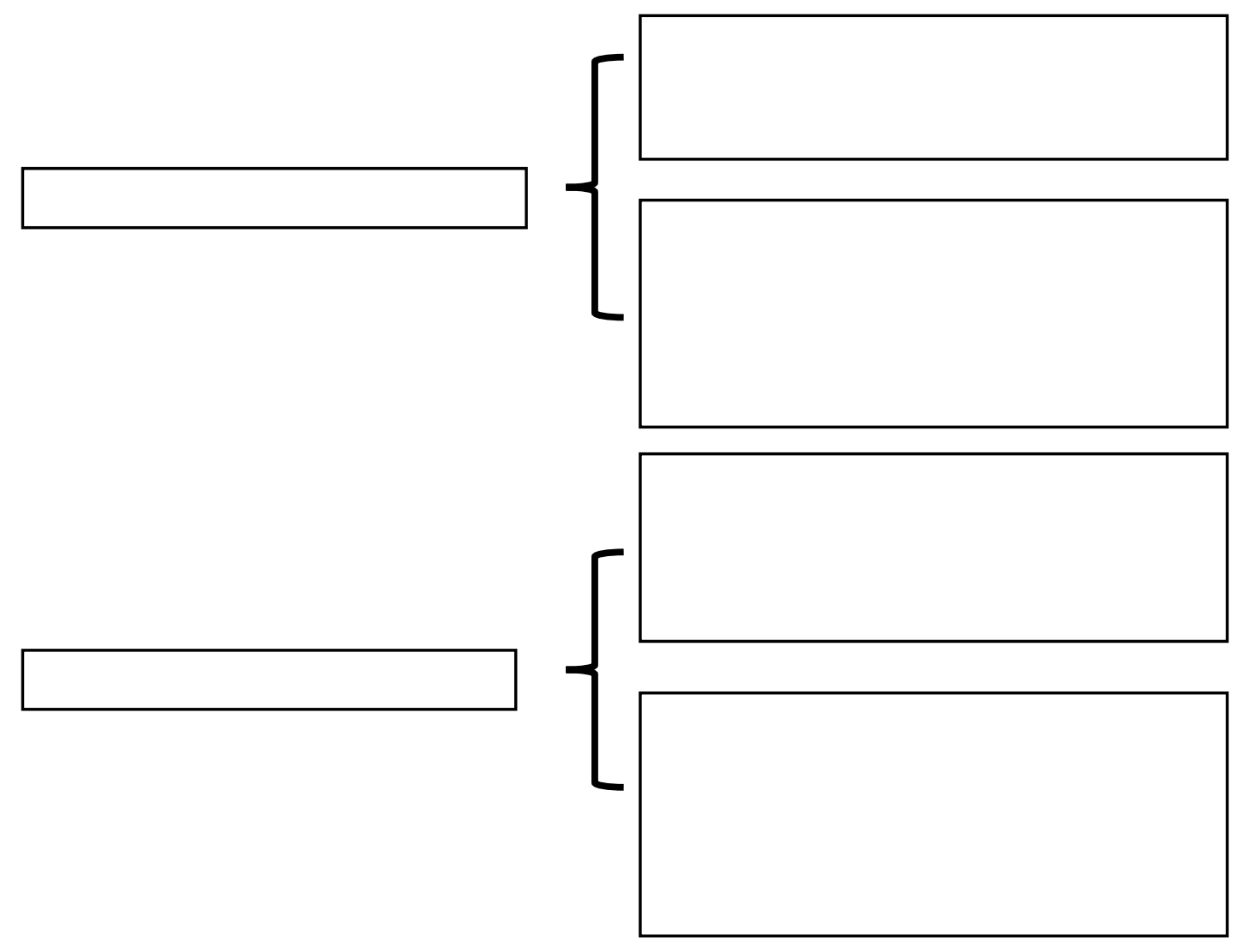

En todo caso, se ha de tener en cuenta que el Estatuto de Roma incorpora en su artículo 8 una limitación a su jurisdicción al exigir, para poder activar su competencia, que los crímenes de guerra se han de cometer como parte de un plan o política o como parte de la comisión en gran escala de tales crímenes (Liñán Lafuente, 2016: 395).

El sujeto pasivo de este tipo de crímenes siempre son personas individualizables, aunque en función de la conducta realizada se podría identificar a un sujeto pasivo más genérico, como sucedería en el caso de utilización de armas especialmente dañinas para las personas y para el medio ambiente.

Al examinar los distintos comportamientos que son considerados crímenes de guerra en el art. $8 \mathrm{ER}$, se puede apreciar la diversidad de los bienes jurídicos que se protegen en función de las distintas conductas típicas. Así se pueden distinguir:

- Delitos contra las personas: vida, salud, libertad e indemnidad sexual, integridad física $\mathrm{y} / \mathrm{moral}$, libertad.

- Delitos contra el patrimonio: propiedad y/o posesión, interés cultural, etc.

- Delitos que provocan la vulneración de derechos de defensa (conductas contra el debido proceso, declarar abolidos o suspendidos o inadmisibles ante un tribunal los derechos y acciones de los nacionales de la parte enemiga). 
- Delitos provocados por utilizar métodos de combate prohibidos que afectan a la seguridad de las personas involucradas en el conflicto (ataques sobre objetivos no militares, ataques contra objetos civiles, ataques contra objetos especialmente protegidos, ataques contra personas u objetos protegidos por los signos de la Cruz Roja, Media Luna Roja, León y Sol Rojos, ataques de los que se prevén daños colaterales desproporcionados a personas, objetos 0 daños duraderos y graves al medio ambiente, ataques contra personal o medios de las misiones humanitarias o de mantenimiento de la paz, uso de métodos pérfidos y traicioneros, etc.).

Únicamente se castiga la comisión dolosa de los crímenes de guerra, por lo que el autor de los mismos, sea militar o civil, tendrá que conocer que se está desarrollando un conflicto armado así como la ilicitud del hecho que lleva a cabo. El conocimiento deberá abarcar, pues, todos los elementos del tipo (aunque respecto del conflicto no sea necesario exigir un conocimiento exacto o exhaustivo, siendo suficiente el conocimiento de su existencia), que se habrá de conjugar con la voluntad del autor de cometer el crimen.

Al analizar las conductas subyacentes de los crímenes de guerra, se puede colegir que en cualquier conflicto armado se suele cometer alguno de los comportamientos descritos en el art. $8 \mathrm{ER}$, desde los más graves (ataque a la población civil, torturas, etc.) a los menos graves, como apoderarse de bienes del adversario, etc. El hecho de que habitualmente se pueda apreciar la comisión de crímenes de guerra (bombardeos contra objetivos civiles, contra lugares protegidos, etc.) que quedan sin castigo provoca, en mi opinión, la devaluación de la figura criminal. De nada sirve tipificar más de 30 conductas distintas (art. 8 ER) como crímenes de guerra si con posterioridad estos crímenes no son perseguidos. Bien es cierto que el Estatuto de Roma exige que los crímenes de guerra sean graves para poder activar su competencia, y que la misma es subsidiaria, pero si se opta por tipificar la figura penal de un modo tan extenso, se ha de dar una respuesta punitiva adecuada, pues de otro modo, la mayoría de las conductas que pueden ser consideradas crímenes de guerra quedan en derecho penal simbólico ${ }^{8}$.

En la $1^{\text {a }}$ Conferencia de Revisión del Estatuto de Roma se plantearon distintos aspectos relacionados con el crimen de guerra. Bélgica presentó una propuesta bastante ambiciosa de reforma del artículo $8 \mathrm{ER}$, la cual no fue aceptada en su totalidad, pero sirvió para que se adaptase la Resolución $n^{\circ} 5$ donde se tipificaron como crímenes de guerra en conflictos internos el empleo de determinadas armas prohibidas desde principios del siglo $\mathrm{XX}$, y que sólo habían sido incluidas en el ámbito de los conflictos internacionales. Así, se incluyeron los artículos 8.d xiii (emplear venenos o armas envenenadas), xiv (emplear gases asfixiantes, tóxicos o similares o cualquier líquido material o dispositivo análogo) y $x v$ (emplear balas que se ensanchen o aplasten fácilmente en el cuerpo humano, como balas de camisa dura que no recubra totalmente la parte interior o que tenga incisiones). Ciertamente carecía de sentido que utilizar armas envenenadas en un

\footnotetext{
${ }^{8}$ Todo ello, sin perjuicio que las dos primeras condenas de la CPI en el caso Lubanga y en el caso Katanga, se haya condenado a los acusados por la comisión de crímenes de guerra. El primero fue condenado por los crímenes de guerra de alistar y reclutar niños menores de 15 años y utilizarlos para participar activamente en los enfrentamientos en la República Democrática del Congo entre septiembre de 2002 y agosto de 2003 (ICC-01/04/06/2842). Katanga fue condenado por crímenes de guerra de homicidios y de matanza premeditada, intento de ataque a la población civil, saqueo de bienes y destrucción de la propiedad, durante el ataque a Bogoro el 24 de febrero de 2003, siendo absuelto de cargos de explotación sexual y violación así como del uso de niños soldado (ICC-01/04-01/07-3484).
} 
conflicto armado internacional fuese considerado crimen de guerra y fuese una conducta atípica si se llevaba a cabo en el marco de un conflicto armado interno.

Como sigue careciendo de cualquier justificación que el art. 8.2.b xx) ER incluya la prohibición genérica de utilizar armas y métodos de guerra que por su propia naturaleza causen daños o sufrimientos innecesarios o surta efectos indiscriminados en la violación de los derechos humanos, para los conflictos armados internacionales y esta prohibición no se contemple en los conflictos armados internos.

No obstante, dicha prohibición carece de efecto práctico, pues el citado artículo sólo entrará en vigor cuando se apruebe un anexo de las armas prohibidas y este se incluya en el Estatuto. Anexo que hasta el momento no ha sido aprobado debido a la poca voluntad de determinados Estados de detallar expresamente cuáles son las armas prohibidas. Este Anexo debería incluir, al menos, armas nucleares, armas biológicas de destrucción masiva, u otras que, por su capacidad mortífera, prevea el que las utiliza que destruirán todo ser viviente en un radio determinado, y el mismo debería ser aplicado a los conflictos internos.

Resulta, cuanto menos contradictorio y desproporcionado, que se considere crimen de guerra utilizar de modo indebido la bandera blanca (8.2.b.vii. ER) o declarar que no se dará cuartel (8.2.b.xii. ER), y que la utilización de una bomba atómica no se considere crimen de guerra porque no esté incluido entre las armas mortíferas que deberían formar parte de un anexo que, a día de hoy y tras 15 años de espera, aún no ha sido aprobado por la Asamblea de los Estados Parte de la CPI.

5. Los crímenes de guerra en el Código Penal Español.

El Código Penal español tipifica los crímenes de guerra en sus artículos 608 a 614 bis bajo el capítulo titulado "De los delitos contra las personas y bienes protegidos en caso de conflicto armado". Comienza el Código Penal en el artículo 608 definiendo a las personas protegidas el caso de conflicto armado, que coincide con la regulación internacional (población civil, heridos, enfermos, combatientes fuera de combate, personal de Naciones Unidas, etc.).

Tras ello nos encontramos con distintos delitos que castigan diferentes violaciones de los Convenios internacionales, aunque no exista una referencia directa a los mismos.

El artículo 609 C.P. castiga los delitos cometidos contra las personas protegidas en el marco de un conflicto armado. Nótese que se castiga el mero hecho de poner en peligro, sin que exija, en este supuesto, la causación de un resultado. Así tipifica los ataques contra la vida, la salud, la integridad o la libertad de las personas protegidas. En los siguientes artículos, (609 a 614 C.P.) se castiga la contravención del Derecho de la Haya, tipificando la utilización de métodos o medios de combate prohibidos o destinados a causar sufrimientos innecesarios o males superfluos en un conflicto armado, así como determinadas conductas contra los derechos de los prisioneros y de la población civil, el ataque y destrucción de bienes culturales e históricos, así como la utilización del engaño, la perfidia y la traición frente a las normas que rigen en una contienda armada.

Como puede apreciarse, desde que comenzó a aplicarse la figura penal de los crímenes de guerra, su núcleo esencial ha permanecido invariable, pues se constituye como una infracción grave de las normas internacionales que rigen en los conflictos armados, si bien se han desarrollado figuras específicas que castigan, por 
un lado, la violación del Derecho internacional humanitario, y por otro, la ejecución de métodos, medios y formas de combate prohibidos.

Bibliografía

ALBRECHT, H. (1999), Gesichte der völkerrechtlichen Strafgerichtsbarkeit im 20. Jahrhundert, Nomos, Baden Baden.

GIL GIL, A. (2015), "Delitos contra el derecho de gentes". En: GÓMEZ TOMILLO, M. (Dir.), Comentarios prácticos al Código Penal, Cizur Menor, Editorial Aranzadi, $3^{\mathrm{a}}$ ed., pp. $750-857$

LIÑÁN LAFUENTE, A. (2016), "Los crímenes de guerra". En: GIL GIL, A. y MACULAN, E. (Dir.), Derecho penal internacional, Madrid, Dykinson, pp. 389414

LIÑÁN LAFUENTE, A. (2015), El crimen contra la humanidad, Dykinson, Madrid.

MARTíNEZ ALCAÑIZ, A. (2014), El principio de justicia Universal y los crímenes de guerra. Tesis doctoral. UNED.

QUINTANO RIPOLLÉS, A. (1955), Tratado de Derecho Penal Internacional e Internacional Penal. CSIC, Madrid.

SLOANE, R. (2009). "The cost of confliction: Preserving the dualism of Jus ad Bellum and Jus in Bello in the contemporary law of war", Yale Journal of International Law, Vol. 34, pp. 47-112.

THE BRITISH CASES. (1922), "The British Cases", The American Journal of International Law, 16(4), pp. 633-640.

WERLE, G. (2011). Tratado de Derecho Penal Internacional (2a ed.), trad. GUTIÉRREZ RODRÍGUEZ, M. (Coord),Tirant lo Blanch, Valencia.

Resoluciones de la Corte Penal Internacional:

ICC, Prosecutor v. Thomas Lubanga Dyilo, TC I, Judgment (ICC-01/04-01/06-2842), 14.03.2012.

ICC, le Procureur c. Germain Katanga, TC II, "Jugement rendu en application de l'article 74 du Statut” (ICC-01/04-01/07), 7.03.2014.

Resoluciones Tribunal Penal Internacional ex Yugoslavia:

ICTY Prosecutor v. Duško Tadić. AC, "Decision on the Defence motion for interlocutory appeal on jurisdiction" (IT-94-1-T), 2.10.1995. 